\title{
Relationship of Amplification and Expression of the C-MYC Gene with Survival among Gastric Cancer Patients
}

\author{
Malihea Khaleghian', Abbas Shakoori ${ }^{1}$, Amirnader Emami Razavi², Cyrus \\ Azimi ${ }^{1 *}$
}

\begin{abstract}
Background: During the past decades, the incidence and mortality rate of stomach cancer has demonstrated a great decrease in the world, but it is still one of the most common and fatal cancers especially among men worldwide, including Iran. The $M Y C$ proto-oncogene, which is located at 8q24.1, regulates $15 \%$ of genes and is activated in $20 \%$ of all human tumors. MYC amplification and overexpression of its protein product has been reported in $15-30 \%$ of gastric neoplasias. The aim of this investigation was to find the relative efficacy of CISH (chromogenic in situ hybridization) or IHC (immunohistochemistry) in diagnosis and prognosis of gastric cancer, as well as the relationship of amplification and expression of $C$-MYC gene with patient survival. Materials and Methods: In this cross-sectional study, 102 samples of gastric cancer were collected from patients who had undergone primary surgical resection at the Cancer Institute Hospital, Tehran University of Medical Sciences, from July 2009 to March 2014. All samples were randomly selected from those who were diagnosed with gastric adenocarcinomas. CISH and IHC methods were performed on all of them. Results: Patients were classified into two groups. The first consisted of stage I and II cases, and the second of stage III and IV. Survival tests for both groups was carried out with referrnce to CISH test reults. Group II (stage III \& IV) with CISH+ featured lower survival than those with CISH- $(\mathrm{p}=\mathbf{0 . 2 3 3})$, but group I (stage I \& II) patients demonstrated no significant variation with CISH+ or CISH- ( $p=0.630$ ). Kaplan-Meier for both groups was carried out with IHC test findings and showed similar results. This data revealed that both diffuse and intestinal types of gastric cancer occurred significantly more in men than women. Our data also showed that CISH+ patients $(43 \%)$ were more frequent in comparison with IHC+ patients $(\mathbf{1 4 . 7 \%})$. Conclusions: For planning treatment of gastric cancer patients, by focusing on expanding tumors, which is the greatest concern of the surgeons and patients, CISH is a better and more feasible test than IHC, in regard to sensitivity and specificity. Therefore, CISH can be used as a feasible test for tumor growth and prognosis in stage III and IV lesions. This study also indicated that $C$-MYC amplification in gastric cancer is correlated with survival in advanced stages.
\end{abstract}

Keywords: $\boldsymbol{C}$-MYC gene - CISH - IHC - gastric cancer - survival

Asian Pac J Cancer Prev, 16 (16), 7061-7069

\section{Introduction}

Cancer is the second and third cause of mortality in developed and developing countries, respectively (Bener et al., 2008; Bray et al., 2013). It has been suggested that until 2020, the number of new cancer cases and their related deaths will be increased to 15 and 12 million, respectively (Han et al., 2011). Gastric cancer is the fourth most common cancer and also the second leading cause of cancer- related death in the world (Almasi et al., 2015). During the past decades, the incidence and mortality rate of stomach cancer has indicated a great decrease worldwide, while it is still one of the most common and fatal cancers (Jemal et al., 2011; Zhu and Sonenberg, 2012; Ferlay et al., 2013; Zhou et al., 2015) especially among men (Chong et al., 2014) and is the same in Iran (Sadjadi et al., 2007; Movahedi et al., 2009). Population studies in Iran revealed that the incidence of gastric cancer to be 26.1 among men and 11.1 in women per 100,000 people (Sadighi et al., 2005; Somi et al., 2008). The worldwide prevalence of stomach cancer is about one million new cases annually (Hartgrink et al., 2009), and is the most common cancer in the Iranian population (Somi et al., 2015). The chance of early detection of stomach cancer is small, and most patients are diagnosed at advanced stage and poor prognosis (Derakhshan et al., 2004; Parkin et al., 2005; Chen et al., 2008; Zhou et al., 2015). Therefore, conventional therapy for metastatic gastric cancer remains calmative, with a mediocre survival for metastatic disease of less than one year (Garcia et al., 2007). Of course endoscopy and modern imaging technology have improved the detection of gastric cancer and has shown 
promising results (Hamashima, 2015). Recently, some community-based case-control investigations have been carried out to evaluate the effectiveness of endoscopic screening, and showed a $30 \%$ and $57 \%$ reduction in gastric cancer mortality rate in Japan (Hamashima et al., 2008; Hamashima et al., 2013) and South Korea (Cho, 2014), respectively. It is unclear why gastric cancer aggressively invades the gastric wall and frequently presents at such an advanced tumor stage.

$C-M Y C$ is an oncogene coding a transcription factor that plays a fundamental role in cell proliferation, growth, differentiation, and apoptosis (Fan et al., 2001). C-MYC is widely expressed during embryogenesis and in adult tissues which possess high proliferative content, such as the skin epidermis and the gut (Fan et al., 2001). Complete loss of $C$ - $M Y C$ function results in embryonic lethality (Holian et al., 2002), and in conditional $C-M Y C$ knockout studies, cells lacking $C$-MYC stop to proliferate and exit the cell cycle (Rhyu et al.,1994). Overexpression of $C$-MYC in cultured cells and transgenic animals blocks differentiation and persuades neoplastic transformation (Holian et al., 2002). The knockdown of $C$-MYC can also prevent the growth and proliferation of gastric cancer cells (Wong and Gumbiner, 2003). Great or deregulated expression of $C-M Y C$ has been detected in a wide range of human cancer types and is often correlated with aggressive, poorly-differentiated tumors, such as those of the breast, colon, and small-cell lung carcinoma, osteosarcoma, glioblastoma, and malignant melanoma (Fan et al., 2001). In a wide variety of human cancer types, constitutive overexpression of $C$-MYC largely results from chromosomal translocation and gene amplification (Brooks-Wilson et al., 2004). Gene amplification is the most frequent $C$-MYC abnormality in non-hematological malignancies (Robertson and Jankowski, 2008).

Several studies have presented that $C-M Y C$ amplification in gastric cancer ranged from $38.1 \%$ to $40 \%$ (Ryan and Birnie, 1996; Hundahl et al., 2000). However, only a few studies have shown the clinicopathological implications of $C-M Y C$ amplification in stomach cancer, while hardly any study has described the implications in gastric cancer (Oliveira et al., 2006; Dang et al., 2006; Vita and Henriksson, 2006). In this study the prognostic factors which were correlated with $C$-MYC amplification in stomach cancer were also assessed (Lai et al., 2008; Weinberg, 2008; Diolaiti et al., 2014).

Some researchers from South Korea studied the effects of $C$-MYC amplification on tumor stage and diseasespecific survival of 128 patients with mucinous gastric carcinoma (MGC) and compared the results with those of 302 patients with nonmucinous gastric carcinoma (non-MGC). Patients and C-MYC amplification was found in $10.2 \%$ of MGCs and $6.0 \%$ of non-MGCs. $C-M Y C$ amplification was more frequently found in MGCs of higher tumor stage than in MGCs of lower stage $(\mathrm{p}=0.038) . C-M Y C$ amplification in MGC was correlated with greater invasion depth $(\mathrm{p}=0.007)$. The mean survival time of patients with $C-M Y C$ amplification was shorter than that of patients without $C-M Y C$ amplification in MGC (Choi et al., 2012).

Lin et al. (2014) followed up 64 patients diagnosed with gastric adenocarcinima who had undergone gastrectomy, for a period of four years, in Taiwan. They found 31 deaths attributed to stomach cancer. They applied Kaplan-Meier analysis and showed that retrieval of less than 15 lymph nodes from a patient was a significant predictor of survival. A significant predictor of poorer survival was also higher grading.

In a study among 326 patients with gastric cancer, in Taiwan, Fang et al. (2013) showed that familial gastric cancer was associated with an early stage at diagnosis and a better prognosis compared with sporadic gastric cancers. They found that there were the molecular and survival differences between sporadic and familial stomach cancers. Oh et al. (2014) also in a meta-analysis reported that a first-degree family history of cancer or gastric cancer family history was significantly associated with better survival of gastric cancer patients.

\section{Materials and Methods}

\section{Patients and tissue samples}

Samples were obtained from 102 gastric cancer patients who had undergone primary surgical resection, at the Cancer Institute Hospital, Tehran University of Medical Sciences, between July 2009 to March 2014. Samples were included 102 paraffin-embedded blocks, and also 50 blocks from adjacent normal gastric mucosa as a negative control samples.

The clinicopathological features of the patient samples are shown in Table 1. Gastric cancer samples were classified according to Lauren (1965). The patients were staged using the standard methods of tumor, nodes, and metastasis (TNM) staging (Sobin et al., 2011). All patients had neither chemotherapy nor radiotherapy treatments, before surgery, and there were no other co-occurrences of diagnosed cancers.

Conducting any laboratory/research tests in this investigation was approved by the Ethics Committee, DNA Bank, Cancer Institute of Iran. This study was carried out with the patients' consent, which allowed any molecular/cytogenetic research to be performed on specimens obtained during surgical resection.

\section{Chromogenic in situ hybridization}

CISH was performed on 3- $\mu$ m-thick formalin-fixed paraffin-embedded tissue sections, dewaxed with xylene, and then rehydrated with $100 \%$ ethanol and water. Target retrieval and enzyme digestion were applied using a commercially available tissue pretreatment kit (no.C3018-40: Zytovision laboratories, ZytoDot, Germany).

The sections were dehydrated in upgrading ethanol series and air dried. Ten microliteres of digoxigeninlabeled $C-M Y C$ probe was used on the tissue section, enclosed by a coverslip, sealed, and denaturated on a PCR plate for 5 minutes at $94^{\circ} \mathrm{C}$. Hybridization was carried out overnight at $37^{\circ} \mathrm{C}$. Next day, the cover slip was removed by soaking in standard saline citrate (SSC) solution at room temperature and washed in SSC for 5 minutes at $75^{\circ} \mathrm{C}$. The remaining hybridized probe linked to digoxigenin was detected by mouse antidigoxigenin antibody followed by polymerized horseradish peroxidase 
antimouse immunoglobulin. Peroxidase was developed with diaminobenzidine, and nuclei were counterstained with hematoxylin. All detection reagents were supplied in commercially available kits. The interpretation of CISH results was carried out by the first author (M.K.) with a light microscope using the $\mathrm{x} 40$ objective (original magnification, x100; Figure 1, A-D). Signals were seen as nuclear dark brown dots. Fifty to 100 non overlapping tumor cell nuclei were assessed for each sample. When

Table 1. Clinical and Laboratory Results of Patients According to the two types of Diffuse and Intestinal Gastric Caners

\begin{tabular}{|c|c|c|c|c|}
\hline \multirow[t]{3}{*}{ Variable } & \multicolumn{4}{|c|}{ Type of Gastric Cancer } \\
\hline & \multicolumn{2}{|c|}{ Diffuse } & \multicolumn{2}{|c|}{ Intestinal } \\
\hline & $\mathrm{N}(\%)$ & p-value & $\mathrm{N}(\%)$ & p-value \\
\hline Age & & 0.793 & & 0.132 \\
\hline$<60$ & $28(48.3)$ & & 17(38.6) & \\
\hline$>60$ & $30(51.7)$ & & 27(61.4) & \\
\hline Sex & & $<0.0001$ & & 0.0001 \\
\hline Male & $44(75.9)$ & & $34(77.3)$ & \\
\hline Female & $14(24.1)$ & & $10(22.7)$ & \\
\hline Location of Tumor & & 0.0001 & & 0.009 \\
\hline Fundus & $25(43.1)$ & & $11(25)$ & \\
\hline Pylorus & $3(5.2)$ & & $2(4.5)$ & \\
\hline Esophagus & $6(10.3)$ & & $3(6.8)$ & \\
\hline Cardia & $2(3.4)$ & & $1(2.3)$ & \\
\hline Lesser curativure & $5(8.6)$ & & $8(18.2)$ & \\
\hline Corpus-body & 11(19) & & 8(18.2) & \\
\hline Antrum & $5(8.6)$ & & $11(25)$ & \\
\hline missing & $1(1.7)$ & & - & \\
\hline Grade & & 0.319 & & 0.11 \\
\hline I & $16(27.6)$ & & $13(29.5)$ & \\
\hline II & $16(27.6)$ & & $21(47.7)$ & \\
\hline III & $24(41.4)$ & & $10(22.7)$ & \\
\hline missing & $2(3.4)$ & & - & \\
\hline Necrosis & & 0.002 & & 0.002 \\
\hline yes & $13(22.4)$ & & $6(13.6)$ & \\
\hline No & $9(15.5)$ & & $11(25)$ & \\
\hline N/A & $28(48.3)$ & & $24(54.4)$ & \\
\hline Missing & $8(13.8)$ & & $3(6.8)$ & \\
\hline Vascular invasion & & 0.001 & & 0.001 \\
\hline Yes & $48(82.8)$ & & $30(68.2)$ & \\
\hline No & $6(10.3)$ & & $13(29.5)$ & \\
\hline missing & $4(6.9)$ & & $1(2.3)$ & \\
\hline Perineural invasion & & 0.002 & & 0.446 \\
\hline Yes & $39(67.2)$ & & $24(54.5)$ & \\
\hline No & $16(27.6)$ & & $19(43.2)$ & \\
\hline missing & $3(5.2)$ & & $1(2.3)$ & \\
\hline Stage & & 0.313 & & 0.651 \\
\hline I & $13(22.4)$ & & $9(20.5)$ & \\
\hline II & $18(31)$ & & $14(31.8)$ & \\
\hline III & $17(29.3)$ & & $12(27.3)$ & \\
\hline IV & $9(15.5)$ & & $9(20.5)$ & \\
\hline missing & 1(1.7) & & $0(0)$ & \\
\hline \multicolumn{5}{|l|}{ CISH Amplification } \\
\hline$<2$ Signals & $32(55.2)$ & 0.0001 & $26(59.1)$ & 0.0001 \\
\hline 2-4 Signals & $14(24.1)$ & & $10(22.7)$ & \\
\hline 4-6 Signal & 4(6.9) & & $2(4.5)$ & \\
\hline (>6 Signal & $8(13.8)$ & & $6(13.6)$ & \\
\hline $\mathrm{IHC}$ & & 0.0001 & & 0.0001 \\
\hline Positive & 11(19) & & 4(9.1) & \\
\hline Negative & $47(81)$ & & $40(90.9)$ & \\
\hline
\end{tabular}

DOI:http://dx.doi.org/10.7314/APJCP.2015.16.16.7061 C-MYC Expression and Survival in Gastric Cancer Patients the gene copy number was one or two per nucleus, it was accounted as "no amplification" (Figure 1A). A gene copy number of 2 to 4 copies per nucleus, in at least $50 \%$ of cancer cells, were scored as "low amplification" (Figure 1B). A gene copy number of 4 to 6 copies per nucleus, in at least $50 \%$ of cancer cells, were considered as "moderate amplification" (Figure 1C). A gene copy number of more than 6 copies per nucleus or the presence of clusters in at least $50 \%$ of cancer cells, was accunted as "high amplification" (Figure 1D) (Tsuboi et al., 1987; Bizari et al., 2006; Shah and Ajani, 2010). Normal cells in tissues were considered as controls. CISH were assessed with a Leitz microscope (Germany). Images were taken with a digital Nikon camera (Japan). All the slides of patients were confirmed for diagnosis and were checked for CISH and IHC by one author.

\section{Immunohistochemistry}

Immunohistochemical staining was carried out according to Calcagno et al. (2009). IHC analyses for MYC were performed on formalin-fixed, paraffin-embedded surgical sections. Serial 3- $\mu \mathrm{m}$ sections were used. Heat induced antigen retrieval was down (microwave-BotanIran). Slides were incubated in hydrogen peroxide, and antigen retrieval was applied by heat treatment in $0.294 \%$ $\mathrm{wt} / \mathrm{vol}$ citrate buffer at $\mathrm{pH} 6.0$ in a domestic microwave oven (Botan-Iran) as follows: $900 \mathrm{~W}$ for 5 minutes and then $600 \mathrm{~W}$ for 10 minutes, avoiding slides were dried out. IHC staining was performed using the LSAB method. Primary antibody were used against MYC (monoclonal rabbit, Ready to use, PME 415 AA Biocare Medical, USA) as recommended by the manufacturer.

A universal peroxidase-conjugated secondary antibody kit (AmpliStain Anti-Mouse/Rabbit 1-Step HRP, Germany) was used for the detection with diaminobenzidine (DAB) as chromogen (SDT, Germany). Positive protein expression was defined as clear nuclear staining in more than $15 \%$ of the cells.

\section{Statistical analysis}

The statistical calculation was performed using version 18 of SPSS statistical software package for Windows (UK). Kappa statistics were used to measure the degree of agreement between CISH and IHC tests, and chi-squared tests were applied for all the variables in Table 1. Variables in Table 2, with two rows were tested by the Mann-Whitney test, and variables with more than two rows were tested with Kruskal-Wallis. For determining the association between CISH and IHC, Kappa test and the Spearman correlation coefficient were applied. Description of the results of Kappa test were as follows: less than 0.20 (poor agreement); 0.20 to 0.40 (fair agreement); 0.40 to 0.60 (moderate agreement); 0.60 to 0.80 (good agreement); 0.80 to 1.00 (very good agreement) (Altman, 1990). p-value less than 0.05 were considered as significant level in all tests. Survival analysis according to the univariate Kaplan-Meier method was calculated. Groups with their survival were tested by chi- squared. 


\section{Results}

Our samples were from 102 Iranian patients with gastric adenocarcinomas, consisted of 78 males (76.47\%) and 24 females $(23.53 \%)$, with an average age of 60.62 years old. MYC amplification and its protein expression (CISH and IHC tests) were applied on our samples.

\section{Clinical results}

The clinicopathological features of our samples are shown in Table 1. The location of the tumor in $35.3 \%$ of patients was fundus, and in cardia was only $3 \%$. Type of stomach cancers was diffuse $(56.9 \%)$ and intestinal $(43.1 \%)$. The average tumor size of patients was $6.49 \mathrm{~cm}$. Our results showed that some of the variables including gender, location of tumor, necrosis, vascular invasion, perineural invasion, CISH and IHC were significant difference among diffuse type and also gender, location of tumor, vascular invasion, necrosis, CISH and IHC were significant difference in intestinal type (Table 1). It means that subgroups of each variable are different in the two types of gastric cancer. Our data also showed that there was no correlation between age, grade and stage with type

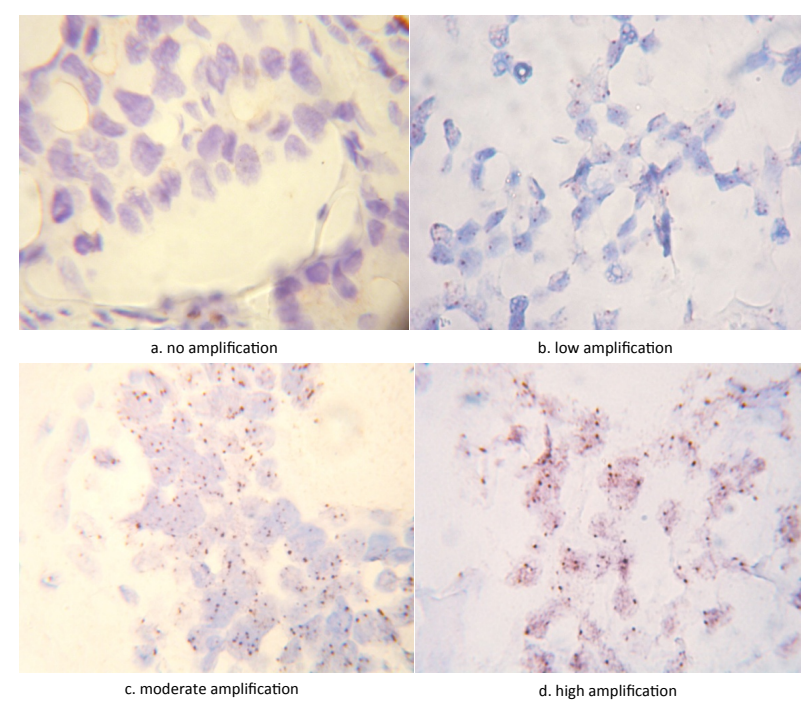

Figure 1. The Results of MYC Amplification by CISH Test. (A) no amplification (0-1 signal). (B) low amplification (2-4 signals). (C) moderate amplification (5-6 signals). (D) high amplification (more than 6 signals, which looks as large copy gene clusters in the majority of the nuclei of gastric cancer cells). [original magnification, X500]

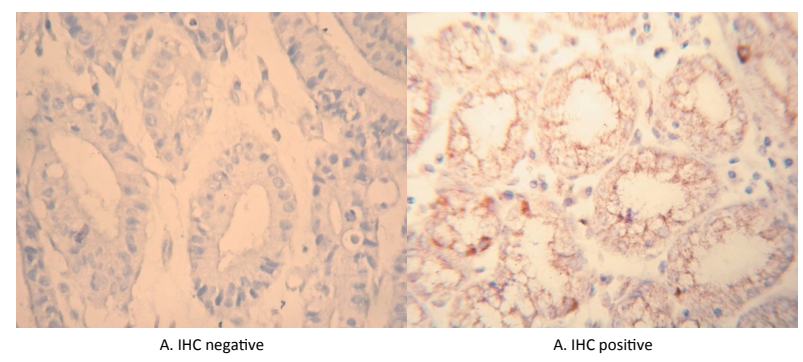

Figure 2. The results of C-MYC Expression by IHC Test. (A) Negative IHC in gastric adenocarcinoma. (B) Positive IHC in gastric adenocarcinoma of gastric cancer. Table 1 showed the gender difference among our samples as both diffuse and intestinal types of stomach cancer occurred significantly more in men than women. Table 1 showed that the most of our patients were in grades II and III, and also in stages II and III, 69.6\%

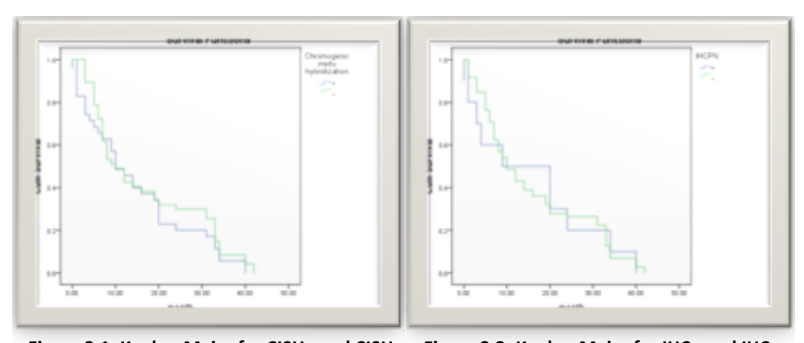

Figure 3.1. Kaplan-Meier for CISH+ and CISH- Figure 3.2. Kaplan-Meier for IHC+ and IHC-
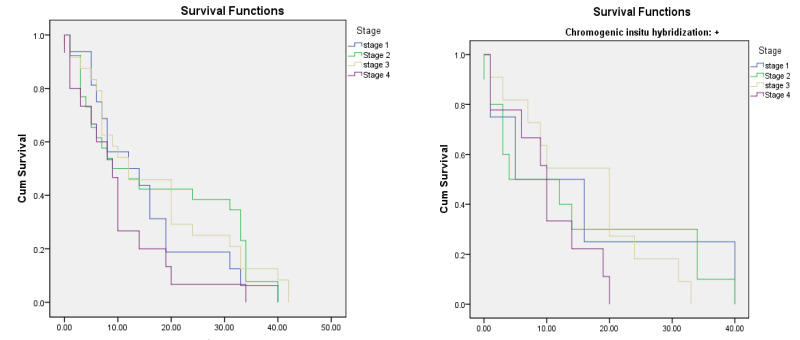

3.3. Kaplan-Meier for different stages
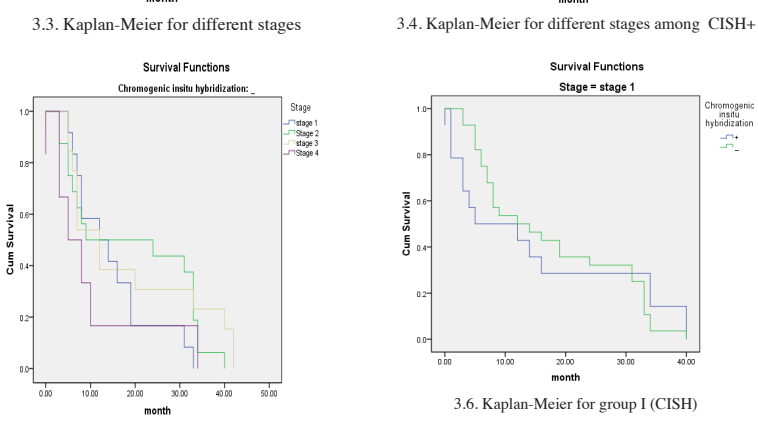

3.6. Kaplan-Meier for group I (CISH)

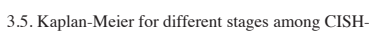

Survival Function

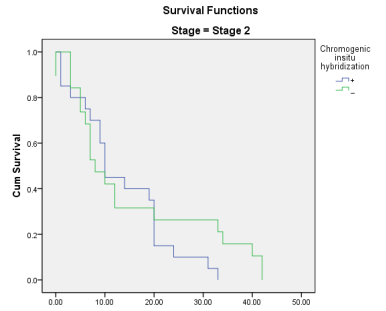

3.7. Kaplan-Meier for group II (CISH) $\begin{gathered}\text { Survival Functions } \\ \text { Stage }=\text { Stage } 2\end{gathered}$
S

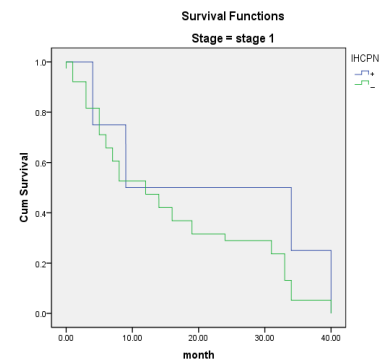

3.8. Kaplan-Meier for group I (IHC)

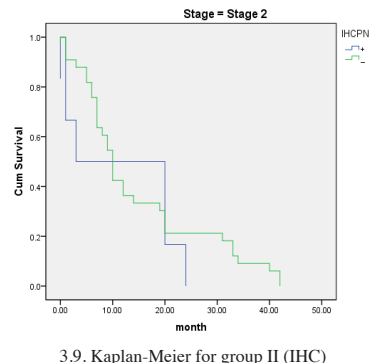

Figure 3.3.1. Kaplan-Meier for CISH+ and CISH-; 3.2. Kaplan-Meier for IHC+ and IHC-; 3.3. Kaplan-Meier for different stages; 3.4. Kaplan-Meier for different stages among CISH+; 3.5. Kaplan-Meier for different stages among CISH-; 3.6. Kaplan-Meier for group I (CISH); 3.7. Kaplan-Meier for group II (CISH); 3.8. Kaplan-Meier for group I (IHC); 3.9. Kaplan-Meier for group II (IHC) 
and $59.8 \%$, respectively.

\section{CISH results}

The results of CISH and IHC are shown in Table 1.

Table 2. The results of Correlation between C-MYC Amplification and C-MYC Expression among 102 Patients with Stomach Cancers

\begin{tabular}{lcrc}
\hline & \multicolumn{3}{c}{ CISH } \\
\cline { 2 - 4 } IHC & Positive & Negative & Total \\
\hline Positive & $13(12.7 \%)$ & $2(2 \%)$ & $15(14.7 \%)$ \\
Negative & $31(30.3 \%)$ & $56(55 \%)$ & $87(85.3 \%)$ \\
Total & $44(43 \%)$ & $58(57 \%)$ & $102(100 \%)$ \\
\hline
\end{tabular}

*Value agreement $=0.284$, percent of agreement $=28.4 \%, \mathrm{P}$-value $=$ 0.0001 ; Statistically significantly different from zero
DOI:http://dx.doi.org/10.7314/APJCP.2015.16.16.7061

C-MYC Expression and Survival in Gastric Cancer Patients

Our data showed that there was no correlation between ages, gender, tumor location, necrosis, vascular invasion, perineural invasion, stages and type of gastric cancer with CISH test. Our results revealed that there was an indication of some relation between grades and CISH, although the difference was not significant. This study also showed that CISH+ patients $(43.1 \%)$ were more frequent in comparison with $\mathrm{IHC}+$ patients $(14.7 \%)$. Table 3 shows the correlation between CISH and IHC. Differential amplification of CISH test was shown in Table 2. According to our CISH data 58 samples showed no amplification and among 44 samples with CISH+, 24 samples were with low amplification. 6 samples showed moderate amplification and 14 samples showed high amplification. We also considered low amplification as

Table 3. Clinical and Laboratory Results of Patients According to C- MYC Amplification (CISH) and C-MYC Expression (IHC)

\begin{tabular}{|c|c|c|c|c|c|c|c|c|}
\hline \multirow[t]{3}{*}{ Variable } & \multicolumn{3}{|c|}{ IHC } & \multicolumn{5}{|c|}{ CISH } \\
\hline & \multirow{2}{*}{$\frac{\text { Positive }(\mathrm{n}=15)}{\mathrm{N}(\%)}$} & \multicolumn{2}{|c|}{ Negative $(n=87)$} & \multirow{2}{*}{$\frac{\mathrm{No}(\mathrm{n}=58)}{\mathrm{N}(\%)}$} & \multirow{2}{*}{$\frac{\text { Low }(\mathrm{n}=24)}{\mathrm{N}(\%)}$} & \multirow{2}{*}{$\frac{\text { Moderate }(\mathrm{n}=6)}{\mathrm{N}(\%)}$} & \multicolumn{2}{|c|}{ High $(n=14)$} \\
\hline & & $\overline{N(\%)}$ & $\overline{\mathrm{p} \text { value }}$ & & & & $\mathrm{N}(\%)$ & $\overline{\mathrm{p} \text { value }}$ \\
\hline Age & & & 0.83 & & & & & 0.32 \\
\hline$<60$ & $7(46.7)$ & $38(43.7)$ & & $27(46.6)$ & $12(50)$ & $3(50)$ & $3(21.4)$ & \\
\hline$>60$ & $8(53.3)$ & $49(56.3)$ & & $31(53.4)$ & $12(50)$ & $3(50)$ & $11(78.6)$ & \\
\hline Sex & & & 0.728 & & & & & 0.336 \\
\hline Male & $12(80)$ & $38(43.7)$ & & $43(74.1)$ & $17(70.8)$ & $6(100)$ & $12(85.7)$ & \\
\hline Female & $3(20)$ & $49(56.3)$ & & $15(25.9)$ & $7(29.2)$ & $0(0)$ & $2(14.3)$ & \\
\hline Location & & & 0.824 & & & & & 0.33 \\
\hline Fundus & $7(46.7)$ & $29(33.3)$ & & $14(24.1)$ & $13(54.2)$ & $3(50)$ & $6(42.9)$ & \\
\hline Pylorus & $1(6.7)$ & $4(4.6)$ & & $3(5.2)$ & $0(0)$ & $1(16.7)$ & $1(7.1)$ & \\
\hline Esophagus & $1(6.7)$ & $8(9.2)$ & & $7(12.1)$ & $0(0)$ & $0(0)$ & $2(14.3)$ & \\
\hline Cardia & $0(0)$ & $3(3.4)$ & & $2(3.4)$ & $0(0)$ & $0(0)$ & $1(7.1)$ & \\
\hline Lesser Curvature & $2(13.3)$ & $11(12.6)$ & & $7(12.1)$ & $4(16.7)$ & $1(16.7)$ & $1(7.1)$ & \\
\hline Corpus-body & $1(6.7)$ & $18(20.7)$ & & $14(24.1)$ & $3(12.5)$ & $1(16.7)$ & $1(7.1)$ & \\
\hline Antrum & $3(20)$ & $13(14.9)$ & & $10(17.2)$ & $4(16.7)$ & $0(0)$ & $2(14.3)$ & \\
\hline missing & - & $1(1.1)$ & & 1(1.7) & $0(0)$ & $0(0)$ & $0(0)$ & \\
\hline Grade & & & 0.002 & & & & & 0.061 \\
\hline I & $1(6.7)$ & $28(32.2)$ & & $20(34.5)$ & $7(29.2)$ & $0(0)$ & $2(14.3)$ & \\
\hline II & $3(20)$ & $34(39.1)$ & & $22(37.9)$ & $9(37.5)$ & $2(33.3)$ & $4(28.6)$ & \\
\hline III & $11(73.3)$ & $23(26.4)$ & & $15(25.9)$ & $8(33.3)$ & $4(66.7)$ & $7(50)$ & \\
\hline missing & - & $2(2.3)$ & & 1(1.7) & $0(0)$ & $0(0)$ & $1(7.1)$ & \\
\hline Necrose & & & 0.79 & & & & & 0.167 \\
\hline Yes & $3(20)$ & $16(18.4)$ & & $14(24.1)$ & $2(8.3)$ & $2(33.3)$ & $1(7.1)$ & \\
\hline No & $4(26.7)$ & $16(18.4)$ & & $9(15.5)$ & $5(20.8)$ & $2(33.3)$ & $4(28.6)$ & \\
\hline $\mathrm{N} / \mathrm{A}$ & $7(46.7)$ & $45(51.7)$ & & $31(53.4)$ & $14(58.3)$ & $2(33.3)$ & $5(35.7)$ & \\
\hline Missing & $1(6.7)$ & $10(11.5)$ & & 4(6.9) & $3(12.5)$ & $0(0)$ & $4(28.6)$ & \\
\hline Vascular invasion & & & 0.248 & & & & & 0.238 \\
\hline Yes & $12(80)$ & $66(75.9)$ & & $43(74.1)$ & $19(79.2)$ & $4(66.7)$ & $12(85.7)$ & \\
\hline No & $1(6.7)$ & $18(20.7)$ & & $13(22.4)$ & $4(16.7)$ & $1(16.7)$ & 1(7.1) & \\
\hline missing & $2(13.3)$ & $3(3.4)$ & & $2(3.4)$ & $1(4.2)$ & $1(16.7)$ & $1(7.1)$ & \\
\hline Perineural invasion & & & 0.072 & & & & & 0.148 \\
\hline Yes & $12(80)$ & $51(58.6)$ & & $33(56.9)$ & $15(62.5)$ & $5(83.3)$ & $10(71.4)$ & \\
\hline No & $2(13.3)$ & $33(37.9)$ & & $23(39.7)$ & $8(33.3)$ & $1(16.7)$ & $3(21.4)$ & \\
\hline missing & $1(6.7)$ & $3(3.4)$ & & $2(3.4)$ & $1(4.2)$ & $0(0)$ & $1(7.1)$ & \\
\hline Stage & & & & & & & & \\
\hline I & $4(26.7)$ & $18(20.7)$ & 0.252 & $15(25.9)$ & $5(20.8)$ & $0(0)$ & $2(14.3)$ & 0.508 \\
\hline II & $5(33.3)$ & $27(31)$ & & $18(31)$ & $6(25)$ & $3(50)$ & $5(35.7)$ & \\
\hline II & $6(40)$ & $23(26.4)$ & & $17(29.3)$ & $6(25)$ & $2(33.3)$ & $4(28.6)$ & \\
\hline IV & $0(0)$ & $18(20.7)$ & & $8(13.8)$ & $6(25)$ & $1(16.7)$ & $3(21.4)$ & \\
\hline missing & $0(0)$ & $1(1.1)$ & & $0(0)$ & $1(4.2)$ & $0(0)$ & $0(0)$ & \\
\hline Type & & & 0.165 & & & & & 0.706 \\
\hline Diffuse & $11(73.3)$ & $47(54)$ & & $32(55.2)$ & $14(58.3)$ & $4(66.7)$ & $8(57.1)$ & \\
\hline Intestinal & $4(26.7)$ & $40(46)$ & & $26(44.8)$ & $10(41.7)$ & $2(33.3)$ & $6(42.9)$ & \\
\hline
\end{tabular}


$\mathrm{CISH}+$ (Table 3).

\section{IHC Results}

Table 2 shows the comparison of CISH and IHC. This result revealed that there was a significant difference between grades and IHC. Table 3 shows the results of IHC positive and negative. MYC immunoreactivity was seen in 15 patients. In 13 patients both MYC amplification and MYC immunoreactivity were observed. 56 samples had no amplification and were negative IHC. Also among 44 positive samples for CISH, 13 samples had positive signals for IHC and 31 samples negative signals for IHC. The most of patients with IHC negative had no amplification but only two patients with IHC positive had no amplification. Normal cells had also IHC negative (Table 3). Therefore, our patients were divided into four groups. The first group was both $\mathrm{CISH}+$ and $\mathrm{IHC}+(12.7 \%)$. The second was CISH+ and IHC- (30.3\%).The third was CISH- and $\mathrm{IHC}+(2 \%)$. The fourth group had CISH- and IHC- $(55 \%)$. Among our four groups, kappa test was 0.284 , which indicated fair agreement between CISH and IHC (Table 3). To assess the association between CISH and IHC tests, the Spearman correlation coefficient was calculated, and showed -0.365 , with a $\mathrm{p}$-value $=0.0001$, indicating that these two tests were related. In this study $43 \%$ of samples were positive for CISH, but only $14.7 \%$ of them were positive for IHC.

\section{Survival results}

Survival analysis according to the univariate KaplanMeier method did not show any significant impact of $C$-MYC amplification on patients' survival. Kaplan-Meier was carried out on categories of CISH+ and CISH-. There was no statistically significant difference between the two groups $(\mathrm{p}=0.431)$. The two groups had similar survival (Figure 3.1). Kaplan-Meier was applied on categories of IHC+ and IHC-. The two groups had almost the same survival ( $\mathrm{p}=0.984$ ) (Figure 3.2). Kaplan-Meier was used for different stages, and showed no difference in survival $(\mathrm{p}=0.225)$ (Figure 3.3). Kaplan-Meier calculation showed no statistically significant difference between different stages and the two groups of CISH $+(\mathrm{p}=0.525)$ and CISH$(\mathrm{p}=0.372)$ (Figure 3.4,3.5). Patients were classified into two groups. The first group was contained stages I and II, and the second group stages III and IV. Survival test for both groups was carried out with CISH test (Figure 3.6, 3.7). Results showed that the group II (stages III and IV) with CISH+ have less survival than those with CISH$(\mathrm{p}=0.233$ ), but group I (stages I and II) patients had no significant in survival with CISH+ or CISH- $(\mathrm{p}=0.630)$ (Figure 3.8, 3.9). Kaplan-Meier for both groups was carried with IHC test and showed the similar results. $C-M Y C$ amplification was more frequently found in gastric cancer patients with higher tumor stages (stage III or IV) than in lower tumor stages (stage I or II) $(\mathrm{p}=0.630)$.

\section{Discussion}

One hundred and two patients with gastric cancer consisting of 78 males and 24 females were studied. Our data showed a male:female ratio of 3.25:1, with an average age of 60.62. Our data were in agreement with two other reports; one study of 125 patients ( 85 males and 40 females), in Brazil, which gave the ratio of 2.12:1 and the majority of the patients were older than 59 years, with the mean age of 62 years (Souza et al., 2013). The other Selcukbiricik et al. (2013) from Turkey, showed the results of 796 patients ( 552 men and 244 women), with the M/F ratio of 2.26, and median age of 58 years. Although Lin et al. (2014) studied 64 patients, in Taiwan, and showed the mean age of patients 64.4 years in men, and 66.9 in women, with a male/female ratio of 1.56 . Another research from Iran, also is in agreement to our result and reported that gastric cancer, is the most common cancers among Iranian men (Sadjadi et al., 2007).

In this investigation, the tumor location was classified into seven subgroups (Owens and Appelman, 2014), and the majority of our patients showed fundus location. If we divided our patients into two groups of cardia and non-cardia, we would have only $3 \%$ of cardia and $97 \%$ of non-cardia. Selcukbiricik et al. (2013) from Turkey, showed $12.2 \%$ of cardia among 796 Turkish patients, which is in agreement with our data. de Souza et al. (2013) studied gastric cancer among 125 samples, with only two subgroups of cardia and non-cardia, and showed $58.4 \%$ in non-cardia.

The most of our patients (59.9\%) were diffuse type, but some authors reported intestinal type more than the diffuse type (Chang et al., 2006; Souza et al., 2013). The best explanation for this difference is that their samples were from Japan and Brazil which both is from high-risk area, but our data were from Tehran which accounts as a lowrisk area. It has been already documented that intestinal type of gastric adenocarcinoma was more frequent than the diffuse type in high-risk countries (Hamilton and Aaltonen, 2000)

Some authors were reported the association between overexpression of $C-M Y C$ with over $50 \%$ of cancers in human, and also the effect of this overexpression on invasiveness and worse prognosis in patients. The contribution of MYC to tumorgenesis by persuading uncontrolled cellular growth, angiogenesis, proliferation, and genomic instability has been already documented (Arvanitis and Felsher, 2005). It was suggested that the $C-M Y C$ constitutive expression owing to amplification, mutation, or chromosome translocation involves to the development and progression of various cancers (Louis et al., 2005; Shon et al., 2014). C-MYC persuades point mutations, imperfect replication initiation, DNA breakage, changes of DNA repair, and causes remodeling of the 3D nuclear structure of telomeres and chromosomes, so causing topological positions that initiate genomic instability (Adhikary and Eilers, 2005; Matsui et al., 2013).

Most of the patients in different studies were in the early stage of gastric cancer and also from high-risk areas, such as Japan and Korea. However, another author showed higher MYC amplification in diffuse-type, than in intestinal-type, which was agreed with our results (Calcagno et al., 2009). One study of IHC analysis revealed that MYC expression was more frequent in intestinal-type than diffuse-type (Calcagno et al., 2013). On the contrary, we observed MYC expression more 
frequent in diffuse type.

An association of MYC overepression with the proliferative phases of cells has been documented, and this expression was shown only in proliferative phases of development, but not in quiescent or terminally differentiated cells (Suzuki et al., 1997). Our result revealed that there was a significant difference between grades and IHC. We showed an increase in MYC expression, especially in grades II and III. This result is similar to finding from previous results which revealed that MYC expression is down regulated with cell differentiation, and also another investigation which showed the MYC expression was repressed in grade I of gastric cancers, whereas there was a significant increase of MYC protein expression in grades II and III (Suzuki et al., 1997). In our investigation there was no significant difference between IHC and stage. Whereas, some studies showed high levels of MYC protein expression in early stage (Suzuki et al., 1997). There was no significant difference in the percentage of cells with $C-M Y C$ gene amplification between early (pT1) and advanced (pT2-4) stomach cancers. This study was in agreement with our investigation (Suzuki et al., 1997).

It was suggested that there was no association between $C$-MYC gene amplification and differentiated /undifferentiated carcinomas (Suzuki et al., 1997). However, our data showed that there was an indication of some correlation between CISH and grades, although the difference was not reached to the level of significance.

The range of MYC overexpression was reported from $15.6 \%$ to $100 \%$ at the early stage of stomach cancer (Calcagno et al., 2008). However, in our study only $14.7 \%$ showed MYC immunoreactivity (IHC+) in both types, and $85.3 \%$ had no expression. This was less than previous studies (Souza et al., 2013). The probable reason is that all of our patients were randomly selected from different stages. The most usual mechanism of deregulation of MYC in stomach cancer is MYC amplification (Meyer and Penn et al., 2008). This mechanism leads to enhanced oncogenic products in quantities that exceed the transcriptional capacity (Calcagno et al., 2005). In this regards, we also observed three or more MYC gene copies (dots) in $43 \%$ of gastric tumors among our patients. However in previous studies all of the samples showed amplification. Therefore, this investigation was not corroborated previous studies (Calcagno et al., 2006; Calcagno et al., 2009). The probable cause would be all of our samples were from different stages (mostly late stage), but in the previous two studies, the samples were only from early stages. Our study also showed that amplification of $C-M Y C$ in diffuse type was more frequent than in intestinal type, which was not accord with some previous authors (Calcagno et al., 2006; Calcagno et al., 2009). Also our study revealed no correlation between ages, gender, tumor location, necrosis, vascular invasion, perineural invasion and type of gastric cancer with CISH test. Some studies revealed that any relation between MYC amplification and clinicopathological characteristics (grade, stage, lymph node metastasis, tumor location) in gastric cancer is correlated to ethnicity (Shah and Ajani, 2010; Liu et al., 2011). Because we also could not find any relation
DOI:http://dx.doi.org/10.7314/APJCP.2015.16.16.7061

C-MYC Expression and Survival in Gastric Cancer Patients between MYC amplification and clinicopathological characteristics, therefore, the ethnicity of the afflicted population might lead to no relation between those two parameters.

Among our samples $12.7 \%$ revealed both positive CISH and IHC. Although we observed $C$-MYC amplification (CISH-) and IHC+ in only two patients, it seems that it may be an artifact. $30.3 \%$ of our patients showed $C$-MYC amplification (CISH+), but the protein was not expressed (IHC-) (Table 3). The possible explanation would be that a mechanism may degrade a protein or probably mRNA (Shan et al., 2013). Our data showed that CISH and IHC were correlated, and the percentage of positive CISH and IHC were $43 \%$ and $14.7 \%$, respectively. Therefore, it might be concluded that CISH is a better test than IHC.

Some authors mentioned molecular therapeutic targeting of MYC, and showed that MYC inactivation suppresses tumors in animals (Calcagno et al., 2013). In other words, specific knockdown of $C-M Y C$ may decrease the growth and proliferation of gastric cancer cells, therefore, $C-M Y C$ could be a possible target in gene therapy (Zhang et al., 2010).

Survival analysis was carried on for the 102 patients who survived were up to four weeks after surgery. Survival analysis according to the univariate Kaplan-Meier method did not show significant impact of $C$-MYC amplification on patients' survival. Results showed that the group II (stage III \& IV) with CISH+ have less survival than those with CISH- ( $\mathrm{P}=0.233)$, but group I (stage I \& II) patients had no significant in survival with CISH+ or CISH-(0.630). Kaplan-Meier for both groups was carried with IHC test and showed the similar results.

The mean survival time of patients with $C$ - $M Y C$ amplification (CISH+) was shorter than that of patients without $C$-MYC amplification(CISH-) in gastric cancer. However, there was no statistical difference in the diseasespecific survival between patients with c-MYC-amplified gastric cancer and those with c-MYC-non-amplified gastric cancer. Patients with c-MYC-amplified gastric cancer (CISH+) had a poorer disease-specific survival than those without $C-M Y C$ amplification (CISH-) $(\mathrm{P}=0.630)$.

Han et al. (1999) found that expression of MYC is closely linked to proliferative activity of human gastric cancer, and patients with high expression of MYC had poor survival that is parallel with our study. Another study was recently conducted and showed that patients with high expression and high amplification have lower survival which is also in agreement with our research (Valentino et al., 2013).

In conclusion, this study shows that $C$ - $M Y C$ amplification in gastric cancer is correlated with survival in advanced stages and deeply invasive stomach cancer. The results of our study suggest that $C-M Y C$ amplification in gastric cancer may be a genetic alteration that contributes to the frequent presentation in advanced stage of gastric cancer.

\section{Acknowledgements}

This study was carried out mainly by personal fund, and partially was supported by the grant to Dr. 
Cyrus Azimi from the Cancer Research Center, Tehran University of Medical Sciences (Grant number: 90-0151-13605) for some of the expenses to conduct the first author's Ph.D. project. Therefore, Dr. Cyrus Azimi and Dr. Malihea Khaleghian would like to thank the Cancer Research Center, Tehran University of Medical Sciences.

\section{References}

Adhikary S, Eilers M (2005). Transcriptional regulation and transformation by Myc proteins. Nature Rev Mol Cell Biol, 6, 635-45.

Almasi Z, Rafiemanesh H, Salehiniya H (2015). Epidemiology characteristics and trends of incidence and morphology of stomach cancer in Iran. Asian Pac J Cancer Prev, 16, 2757-61.

Altman DG (1990). Practical statistics for medical research, CRC Press.

Arvanitis C, Felsher DW (2005). Conditionally MYC: insights from novel transgenic models. Cancer Letters, 226, 95-9.

Basaran H, Koca T, Cerkesli AK, et al (2015). Treatment outcomes and survival study of gastric cancer patients: a retrospective analysis in an endemic region. Asian Pac J Cancer Prev, 16, 2055-60.

Bener A, Ayub H, Kakil R, et al (2008). Patterns of cancer incidence among the population of Qatar: a worldwide comparative study. Asian Pac J Cancer Prev, 9, 19-24.

Bizari L, Silva AE, Tajara EH (2006). Gene amplification in carcinogenesis. Genet Mol Biol, 29, 1-7.

Bray F, Ren JS, Masuyer E, et al (2013). Global estimates of cancer prevalence for 27 sites in the adult population in 2008. Inter J Cancer, 132, 1133-45.

Brooks-Wilson A, Kaurah P, Suriano G, et al (2004). Germline E-cadherin mutations in hereditary diffuse gastric cancer: assessment of 42 new families and review of genetic screening criteria. $J$ med genet, 41, 508-17.

Calcagno DQ, Leal MF, Takeno SS, et al (2005). Aneuploidy of chromosome 8 and $C$ - $M Y C$ amplification in individuals from northern Brazil with gastric adenocarcinoma. Anticancer Res, 25, 4069-74.

Calcagno DQ, Leal MF, Seabra AD, et al (2006). Interrelationship between chromosome 8 aneuploidy, $C$-MYC amplification and increased expression in individuals from northern Brazil with gastric adenocarcinoma. World J Gastroenterol, 12, 6207.

Calcagno DQ, Leal MF, Assumpcao PP, et al (2008). MYC and gastric adenocarcinoma carcinogenesis. World $J$ Gastroenterol, 14, 5962.

Calcagno DQ, Guimaraes AC, Leal MF, et al (2009). MYC insertions in diffuse-type gastric adenocarcinoma. Anticancer Res, 29, 2479-83.

Calcagno DQ, Freitas VM, Leal MF, et al (2013). MYC, FBXW7 and TP53 copy number variation and expression in Gastric Cancer. BMC Gastroenterol, 13, 1-10.

Chang MS, Uozaki H, Chong JM, et al (2006). CpG island methylation status in gastric carcinoma with and without infection of Epstein-Barr virus. Clin Can Res, 12, 2995-3002.

Chen XZ, Jiang K, Hu JK, et al (2008). Cost-effectiveness analysis of chemotherapy for advanced gastric cancer in China. World J Gastroenterol, 14, 2715-22.

Cho BY (2014). Evaluation of the validity of current national health screening programs and plans to improve the system. Seoul University, Seoul. pp. 741-58.

Choi JS, Seo J, Jung EJ, et al (2012). C-MYC amplification in mucinous gastric carcinoma: a possible genetic alteration leading to deeply invasive tumors. Anticancer Res, 32,
5031-8.

Chong VH, Telisinghe PU, Abdullah MS, et al (2014). Gastric cancer in brunei darussalam: epidemiological trend over a 27 year period (1986-2012). Asian Pac J Cancer Prev, 15, 7281-5.

Dang CV, O'Donnell KA, Zeller KI, et al (2006). (Editors). The $C-M Y C$ target gene network. seminars in cancer biology, elsevier.

Derakhshan M, Yazdanbod A, Sadjadi A, et al (2004). High incidence of adenocarcinoma arising from the right side of the gastric cardia in NW Iran. Gut, 53, 1262-6.

de Souza CRT, Leal MF, Calcagno DQ, et al (2013). MYC deregulation in gastric cancer and its clinicopathological implications. PLOS One, 8, 64420.

Diolaiti D, McFerrin L, Carroll PA, et al (2014). Functional interactions among members of the MAX and MLX transcriptional network during oncogenesis. Bioch Biophy Acta, 1849, 484-500

Fan XM, Wong BCY, Wang WP, et al (2001). Inhibition of proteasome function induced apoptosis in gastric cancer. Inter J Cancer, 93, 481-8.

Fang WL, Chang SC, Lan YT, et al (2013). Molecular and survival differences between familial and sporadic gastric cancers. Biomed Res Int, 2013, 396272.

Ferlay J, Soeriomataram I, Ervik M, et al (2013). Cancer incidence and mortality worldwide: IARC cancerbase, lyon. international agency for research on cancer (iarc). globocan 2012. www.globocan.iarc.fr.

Garcia M, Jemal A, Ward EM, et al (2007). Global cancer facts and figures 2007. atlanta, GA: american cancer society.

Hamashima C, Shibuya D, Yamazaki H, et al (2008). The Japanese guidelines for gastric cancer screening. Jpn J Clin Oncol, 38, 259-67.

Hamashima C, Ogoshi K, Okamoto M, et al (2013). A community-based, case-control study evaluating mortality reduction from gastric cancer by endoscopic screening in Japan. PLOS One, $\mathbf{8 ,} 79088$.

Hamashima C (2015). Have we comprehensively evaluated the effectiveness of endoscopic screening for gastric cancer? Asian Pac J Cancer Prev, 16, 3591-2.

Hamilton SR, Aaltonen LA (2000). (editors). Pathology and genetics of tumours of the digestive system. the international agency for reseaech on cancer. IARC Press, Lyon.

Han MA, Choi KS, Lee HY, et al (2011). Current status of thyroid cancer screening in Korea: results from a nationwide interview survey. Asian Pac J Cancer Prev, 12, 1657-63.

Han S, Kim HY, Park K, et al (1999). C-MYC expression is related with cell proliferation and associated with poor clinical outcome in human gastric cancer. $J$ Korean Med Sci, 14, 526-30.

Hartgrink HH, Jansen EPM, Van Grieken NCT, et al (2009). Gastric cancer. Lancet, 374, 477-90.

Holian O, Wahid S, Atten MJ, et al (2002). Inhibition of gastric cancer cell proliferation by resveratrol: role of nitric oxide. Am J Physio Gastro Liv Physio, 282, 809-16.

Hundahl SA, Phillips JL, Menck HR (2000). The National Cancer Data Base report on poor survival of US gastric carcinoma patients treated with gastrectomy. Cancer, $\mathbf{8 8}$, 921-32.

Janjigian YY, Tang LH, Coit DG, et al (2011). MET expression and amplification in patients with localized gastric cancer. Cancer Epidemiol Biomarkers Prev, 20, 1021-7.

Jemal A, Bray F, Center MM, et al (2011). Global Cancer Statistics. Ca Cancer J Clin, 61, 69-90.

Lai JF, Kim S, Li C, et al (2008). Clinicopathologic characteristics and prognosis for young gastric adenocarcinoma patients after curative resection. Annals Surg Oncol, 15,1464-9. 
Lauren P (1965). The two histological main types of gastric carcinoma: Diffuse and so-called intestinal-type carcinoma. An attempt at a histo-clinical classification. Acta Pathol Microbiol Scand, 64, 31-49.

Lin WL, Sun JL, Chang SC, et al (2014). Factors predicting survival of patients with gastric cancer. Asian Pac J Cancer Prev, 15, 5835-8.

Liu X, Cai H, Huang H, et al (2011). The prognostic significance of apoptosis-related biological markers in Chinese gastric cancer patients. PLOS One, 6, 29670.

Louis SF, Vermolen BJ, Garini Y, et al (2005). C-MYC induces chromosomal rearrangements through telomere and chromosome remodeling in the interphase nucleus. Proceedings Nat Acad Sci USA, 102, 9613-8.

Matsui A, Ihara T, Suda H, et al (2013). Gene amplification: mechanisms and involvement in cancer. Bio Mol Concepts, 4, 567-82.

Meyer N, Penn LZ (2008). Reflecting on 25 years with MYC. Nature Rev Cancer, 8, 976-90.

Movahedi M, Afsharfard A, Moradi A, et al (2009). Survival rate of gastric cancer in Iran. J Res Med Sci, 14, 367-73.

Oh MG, Kim JH, Han MA, et al (2014). Family history and survival of patients with gastric cancer: a meta-analysis. Asian Pac J Cancer Prev, 15, 3465-70.

Oliveira C, Seruca R, Carneiro F (2006). Genetics, pathology, and clinics of familial gastric cancer. Inter J Surg Path, 14, 21-33.

Owens SR, Appelman HD (2014). Carcinoma of the Stomach. Atlas of Esophagus and Stomach Pathology. Springer.

Parkin DM, Bray F, Ferlay J, et al (2005). Global cancer statistics, 2002. CA Cancer J Clin, 55, 74-108.

Rhyu MG, Park WS, Jung YJ, et al (1994). Allelic deletions of MCC/APC and p53 are frequent late events in human gastric carcinogenesis. Gastroenterol, 106, 1584-8.

Robertson EV,Jankowski JA(2008). Genetics of gastroesophageal cancer: paradigms, paradoxes, and prognostic utility. Am J Gastroenterol, 103, 443-9.

Ryan K, Birnie G (1996). Myc oncogenes: the enigmatic family. Biochem J, 314, 713-21.

Sadighi S, Raafat J, Mohagheghi M (2005). Gastric carcinoma: 5 year experience of a single institute. Asian Pac J Cancer Prev, 6, 195-6.

Sadjadi A, Zahedi M, Nouraie M, et al (2007). The first population-based cancer survey in Kerman Province of Iran. Iran J Pub Health, 36, 26-34.

Selcukbiricik F, Tural D, Bilici A, et al (2013). Clinicopathological features and localization of gastric cancers and their effects on survival in Turkey. Asian Pac J Cancer Prev, 14, 553-6.

Shah MA, Ajani JA (2010). Gastric cancer - an enigmatic and heterogeneous disease. JAMA, 303, 1753-4.

Shan Z, Shakoori A, Bodaghi S, et al (2013). TUSC1, a putative tumor suppressor gene, reduces tumor cell growth in vitro and tumor growth in vivo. PLOS One, 8, 66114.

Shon W, Sukov WR, Jenkins SM, et al (2014). MYC amplification and overexpression in primary cutaneous angiosarcoma: a fluorescence in-situ hybridization and immunohistochemical study. Modern Path, 27, 509-15.

Sobin LH, Gospodarowicz MK, Wittekind C, (2011). (editors). TNM classification of malignant tumours. john wiley and sons; New York.

Somi MH, Farhang S, Mirinezhad SK, et al (2008). Cancer in east azerbaijan, Iran: results of a population - based cancer registry. Asian Pac J Cancer Prev, 9, 327-30.

Somi MH, Ghojazadeh M, Bagheri M, et al (2015). Clinicopathological factors and gastric cancer prognosis in the Iranian population: a meta-analysis. Asian Pac J Cancer Prev, 16, 853-7.
DOI:http://dx.doi.org/10.7314/APJCP.2015.16.16.7061

C-MYC Expression and Survival in Gastric Cancer Patients

Suzuki S, Tenjin T, Watanabe H, et al (1997). Low level C-MYC gene amplification in gastric cancer detected by dual color fluorescence in situ hybridization analysis. J Surg Oncol, 66, 173-8.

Tsuboi K, Hirayoshi K, Takeuchi K, et al (1987). Expression of the $C-M Y C$ gene in human gastrointestinal malignancies. Bioch Biophy Res Commu, 146, 699-704.

Valentino C, Kendrick S, Johnson N, et al (2013). Colorimetric in situ hybridization identifies MYC gene signal clusters correlating with increased copy number, mRNA, and protein in diffuse large B-cell lymphoma. Am J Clin Path, 139, 242-54.

Vita M, Henriksson M, (2006). (editors). The myc oncoprotein as a therapeutic target for human cancer. seminars in cancer biology, elsevier.

Weinberg RA (2008). A biologia do cancer. artmed.

Wong AS, Gumbiner BM (2003). Adhesion-independent mechanism for suppression of tumor cell invasion by E-cadherin. J Cell Biol, 161, 1191-203.

Zhang L, Hou Y, Ashktorab H, et al (2010). The impact of C-MYC gene expression on gastric cancer cell. Mol Cellu Bioch, 344, 125-35.

Zhou YC, Zhao HJ, Shen LZ (2015). Preoperative serum CEA and CA19-9 in gastric cancer - a single tertiary hospital study of 1,075 cases. Asian Pac J Cancer Prev, 16, 2685-91.

Zhu AL, Sonnenberg A (2012). Is gastric cancer again rising? $J$ Clin Gastroenterol, 46, 804-6. 